\title{
Assessing the applicability of GIS in a health and social care setting: planning services for informal carers in East Sussex, England
}

\author{
Ronan Foley* \\ Geography Division, School of the Environment, University of Brighton, Brighton BN2 4GJ, UK
}

\begin{abstract}
Informal carers save the state's health and social care services billions of pounds each year. The stresses associated with caring have given rise to a number of short-term care services to provide respite to carers. The Carers (Recognition \& Services) Act of 1995 identified formally for the first time, the important role that unpaid carers provide across the community in Britain. The planning of combined health and social care services such as short-term care is a less developed application of geographical information systems (GIS) and this paper examines awareness and application issues associated with the potential use of GIS to manage short-term care service planning for informal carers in East Sussex. The assessment of GIS awareness was carried out by using a semi-structured questionnaire approach and interviewing key local managers and planners across a number of agencies. GIS data was gathered from the agencies and developed within a GIS to build up a set of spatial databases of available services, location of users and additional geo-demographic and topographic information. The output from this system development was presented in turn at workshops with agencies associated with short-term care planning as well as users to help assess their perspectives on the potential use and value of GIS. A renewed emphasis on a planned approach to health care coupled with integrated/ joint working with social care creates a need for new approaches to planning. The feedback from planners and users, suggested that a number of key data elements attached to data-sharing may prove to be simultaneously progressive yet problematic, especially in the areas of ethics, confidentiality and informed consent. A critical response to the suitability of GIS as a tool to aid joint health and social care approaches is incorporated within a final summary. (C) 2002 Elsevier Science Ltd. All rights reserved.
\end{abstract}

Keywords: GIS; Health care planning; Social care planning; Carers; Qualitative mapping; UK

\section{Introduction and Aims}

The Carers (Recognition and Services) Act of 1995 (Department of Health, 1995) identified formally for the first time the important role that unpaid Carers play across the community in Britain and this was further recognised in a national strategy document in 1999 (Department of Health, 1999) which ring-fenced $£ 140 \mathrm{~m}$ for additional services for carers. Carers are generally defined as;

\footnotetext{
*Tel: +44-1273-642847; fax: + 44-1273-642285.

E-mail address:mrf2@bton.ac.uk (R. Foley).
}

“.. someone who regularly helps a disabled, ill or frail, relative or friend or neighbour. The help given can range from tasks like dressing, shopping or household tasks, to taking full responsibility for practical personal and emotional support." (Carers National Association, 1994).

Carers save the state's health service and social care services billions of pounds each year by looking after ill or disabled relatives or friends (Department of Health, 1999). The stresses associated with caring have given rise to the development of a number of short-term care services whose broad aim is to relieve carers from the stresses of caring either in the form of a break from 
caring inside or outside the home. These services range from medium to long-term care outside the home, day care and care in the home and are provided by a variety of different statutory, voluntary and private organisations.

As with most health services, the spatial dimension of provision for informal carers is an important issue for service planning. Within an increasingly IT literate society there has been a developing interest in how spatial aspects of service planning and delivery can be managed. Geographical information systems (GIS) have become an increasingly important technology within the broader Geography of Health area in the last ten years (Gatrell \& Löytönen, 1998a; Smith \& Jarvis, 1998). A key element of all service delivery is the notion of planning adequate service delivery to provide equitable and equal services to all potential users of that service. Within a local setting, geography has an important role to play in deciding what services go where and the particular local geographical areas served by those services (Curtis \& Taket, 1996; Curtis \& Jones, 1998). The ability to link maps of services, clients and local populations with relational databases of associated information has allowed managers and planners of health and social services to use this new technology to better run their services. Applications of GIS within the broad health area include epidemiological studies (Hirschfield, Batey, Brown, \& Marsden, 1990), locality planning (Wain, 1997), service site location (Burns, 1995) and optimal routing of emergency services (Gatrell \& Naumann, 1992).

However, GIS research in the informal sector is more limited but with an increasing interest in the wider health/social care nexus (Milligan, 2000), it is apposite to assess ways in which GIS might marry health and social care planning. The application of GIS for the planning of joint health and social care services is far less developed than research on formal health care, though there are some applications such as the planning of services for Alzheimer's Disease sufferers (Dowie, Koval, Burnhill, \& Healy, 1991) and the operation of a GIS-based management system for NHS Trust services in the Leeds/Bradford area (Birkin, Clarke, Clarke, \& Wilson, 1996) which are evidence of research in this area. However, it is the ability and also suitability of a GIS system to manage data which linked the health and social care sectors, a process widely encouraged under recent legislative change in the UK, which points towards the need for the development of this underresearched area of GIS application (Department of Health, 1998; Department of Health, 1999).

The principal aim of the research reported in this paper is to assess the potential applicability of GIS in the study area of East Sussex, Brighton \& Hove (Fig. 1) through a study of informal carers and the provision of short-term care services to those carers. This involves assessment of the existing awareness and usage of GIS within health and social care planning, the identification of potential difficulties in encouraging this awareness and an examination of the problems of developing awareness through the creation of a series of theoretical case studies. The process of identifying local awareness and usage was carried out by qualitative semi structured interviews with a number of key stakeholders in the study area. The case studies were then developed within the context of current service provision policy frameworks and designed to use geographical aspects of those policy frameworks to develop the key GIS data elements. The case studies were used as a tool to research the problems associated with the potential adoption and uptake of GIS technology to manage the community based short-term care services for carers, in particular, carers of children with disabilities in the study area. This assessment was also intended to identify problematic areas of data availability, suitability and management in this complex area to see whether the introduction of GIS were likely to be relevant and appropriate.

\section{GIS, health and informal care provision}

Current approaches to assessing the potential role of GIS in organisational planning and decision-making utilise techniques such as functional needs analysis and benchmarking to assess the wishes of system users and decision-makers and potential beneficiaries (Huxhold \& Levinsohn, 1995; DeMers, 1997). These techniques rely on potential beneficiaries having some knowledge of the data, geographical information and the decision-making process relating to health care planning. In a situation where knowledge of these issues are limited, other approaches may be needed prior to functional needs assessment just to raise awareness of the potential of GIS and the nature of current provision, as such assessments tend to assess needs not problems or potential role. Different potential users have varying data requirements and this is particularly so within certain health and social care sectors (Gatrell \& Löytönen, 1998a; Reeves \& Petch, 1999; Melnick \& Fleming, 1999).

Increasingly, new general texts on GIS (Poulsen, 1994; Chrisman, 1997; Longley, Maguire, Goodchild, \& Rhind, 1999) include at least one chapter on human aspects of the subject whether in the form of organisational take-up or through a consideration of application in much more human-based areas such as planning, health and community services. Couclelis (1997) expanded this approach and identified within GIS a whole area of potential research relating to people and GIS which was a large gap in existing research and which required some work in the social area to more fully 


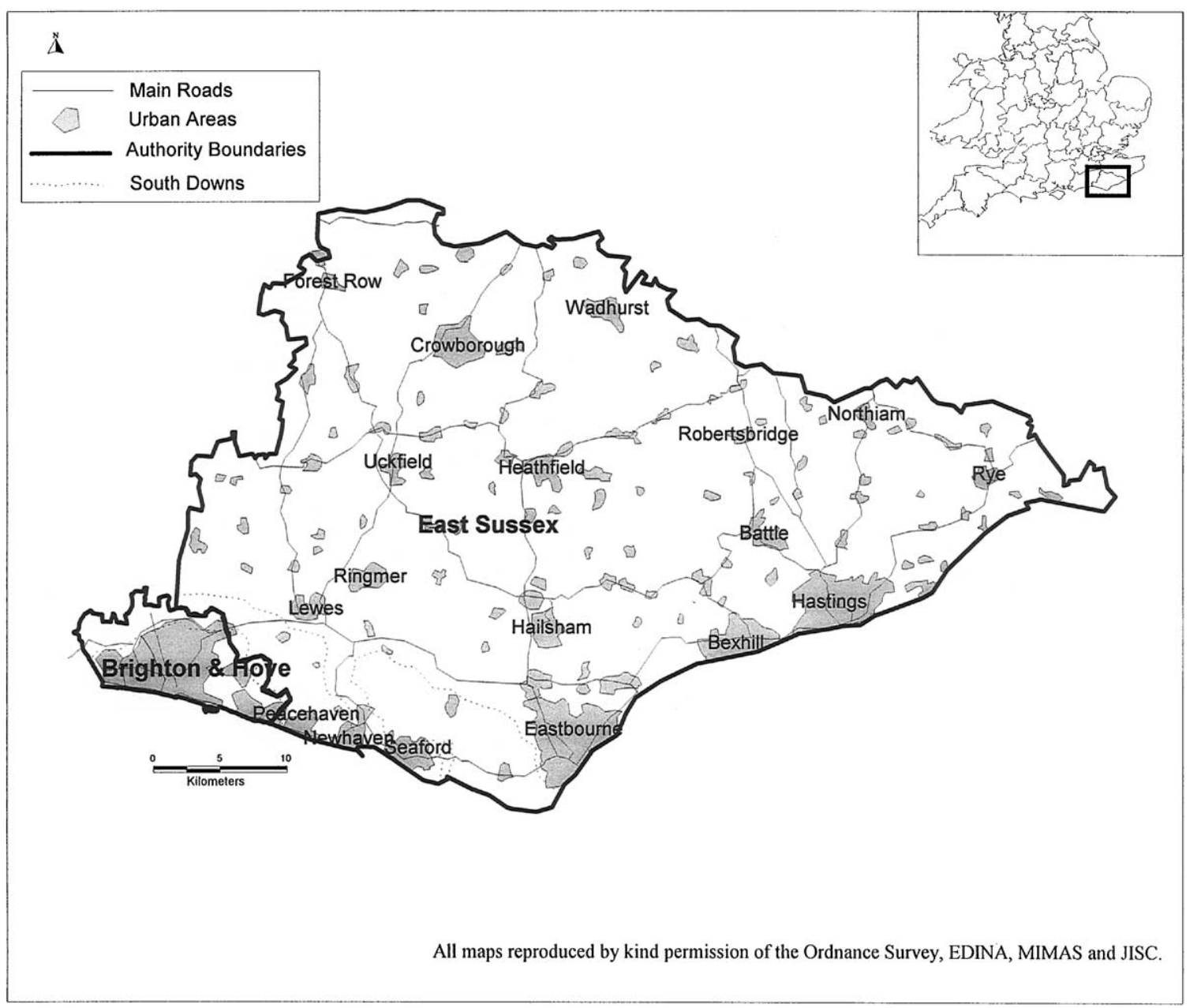

Fig. 1. Map of study area: East Sussex.

account for a gap in GIS understanding. She argued that until GIS attempted to fill this gap, it would remain a theoretical and technically oriented subject which would remain divorced from the real world and needed to explore realistic applications which incorporated at least some understanding of the complexity and variability of human input. This would certainly apply to any GIS research done in the area of health and social care planning and is another reason to develop the research, to see if the technology can be made to work better within a human service environment.

More recently, the use of GIS software has become more widespread in the health and social care fields. In the past few years, there have been a number of summaries in both the UK and the US, which identify very recent applications and developments in the area (Cooper, 1999; Gatrell \& Löytönen, 1998b; Gatrell \& Senior, 1999; Richards, Croner, \& Novick, 1999a). The first three have a UK focus though they include details of worldwide applications as well and also break their descriptions into an epidemiological and health care planning split. Richards et al. (1999a) is one of a number of articles in a special issue of the Journal of Public Health Management \& Practice (Rushton, 1998; Kulldorff, 1999; Melnick \& Fleming, 1999; Roper \& Mays, 1999) which concentrates solely on the use and potential for GIS in public health in the US. Some of these summary articles, particularly the more recent US papers, reflect the widening concerns of the subject, especially in the community and public health areas through the assessment of effectiveness and outcomes, public health resource allocation and organisational and structural changes. A particularly relevant example used ArcView to map community health profiles by census tract and related this to the distribution of health facilities to examine accessibility issues in Northern Delaware (Berry \& Jarrell, 1999). However, there still seems to be a need for further work within GIS which 
incorporates a new awareness, drawn principally from recent geography of health research, that the impact of social, cultural and political contexts must also be identified as core elements within GIS applications in these areas, for them to be effective tools for planning in the broad public health arena (Wilkinson et al., 1998).

From a qualitative point of view, there are a number of other significant elements which need to be considered when dealing with spatial data. As these spatial elements are key linking concepts, it is important to consider how such qualitative information can be embedded within spatial approaches and if not, how then do these qualitative data elements, some of which can be considered as 'aspatial', relate to the more formalised quantitative structures. The structure and organisation of data can therefore, fall into a series of spatial/aspatial elements and this methodology is usefully discussed by Khan and Bhardwaj (1994) who created a valuable methodological structure by breaking the elements down into a matrix. This emphasis on the aspatial is a key one and needs examining in terms of the identification of the key elements, especially within health, which would inform the process of weighting or modification of the quantitative data (Table 1). Phillips (1998) also gives a useful summary of the way in which a quantitative/ qualitative mix is also feasible as a methodology. $\mathrm{He}$ examines the use of a mix of methods in geographical research which would seem to have direct relevance to this work in that a number of different appropriate methodologies are considered in relation to the context, in this case health and social care planning. Such an approach, Phillips argues:

'Accepting the utility of such an approach must involve accepting that epistemology and methodology have a fluid relationship, and that to gain an understanding of a complex world, a variety of methods, in addition to a variety of subject areas must be addressed' (Phillips 1998, p. 272).

A final valuable work in this area and one which perhaps more than most addresses some of the difficulties inherent in the collection and use of data in GIS is provided by O'Dwyer and Burton (1998). They identify from a number of applications in Australia and New Zealand not only a sound summary of the specific areas in which GIS had value but also make clear the difficult conflict, which remains to be solved, which exists between the value of individual level research approaches and the constraints of ethical and legal requirements to maintain patient confidentiality.

As can be seen in the description of the literature mentioned above, there has been virtually no specific literature which relates to the use of GIS as an application within informal care planning. The nearest work, that of planning Alzheimer's care services in Scotland (Dowie et al., 1991) gave some idea of the potential of the subject and was of value in outlining specific methodologies both for planning an integrated service and detailed provision planning in a particular area, as did a number of other more current readings which look at the health-based planning value of GIS (Clarke et al, 1993; Bullen, Moon, \& Jones, 1996; Burns, 1995). Despite the increasing amount of current literature on short-term/respite care, there has been a failure in this research to develop a strong spatial direction and it is hoped that this work would help pull the two strands, GIS and short-term care planning, critically together within the study area using qualitative and quantitative techniques.

\section{Context}

The study area consists of the two health authorities of East Sussex and Brighton \& Hove which at the time of the research (1995/6) were all part of East Sussex, a county on the south coast of England with a total population of approximately 735,000 . The geography of the county is such that the majority of the population lives in three major urban concentrations on the coastal strip, namely, Brighton \& Hove $(250,000)$, Eastbourne $(80,000)$ and Hastings \& Bexhill $(80,000)$ (Fig. 1). The major physical barrier, the South Downs hills, runs north of Brighton across to the western edge of Eastbourne. Inland is a rolling landscape running up to the Kent and Surrey borders with a dispersed rural population with some smaller towns such as Uckfield and Crowborough being the major centres. From a service point of view, the major short-term care services were also concentrated on the coastal strip as illustrated in Fig. 2. The distribution of service users, families of children with disabilities, was more spread out as illustrated in Fig. 3, though again the greatest clusters tended to match the major coastal towns.

Table 1

Typology of access (after Khan \& Bhardwaj, 1994)

\begin{tabular}{lll}
\hline Access & Spatial (geographic) & Aspatial (social) \\
\hline Potential & I. Potential spatial/geographic access & II. Potential access/aspatial access \\
Realized & III. Realized spatial/geographic access & IV. Realized access/social access \\
\hline
\end{tabular}




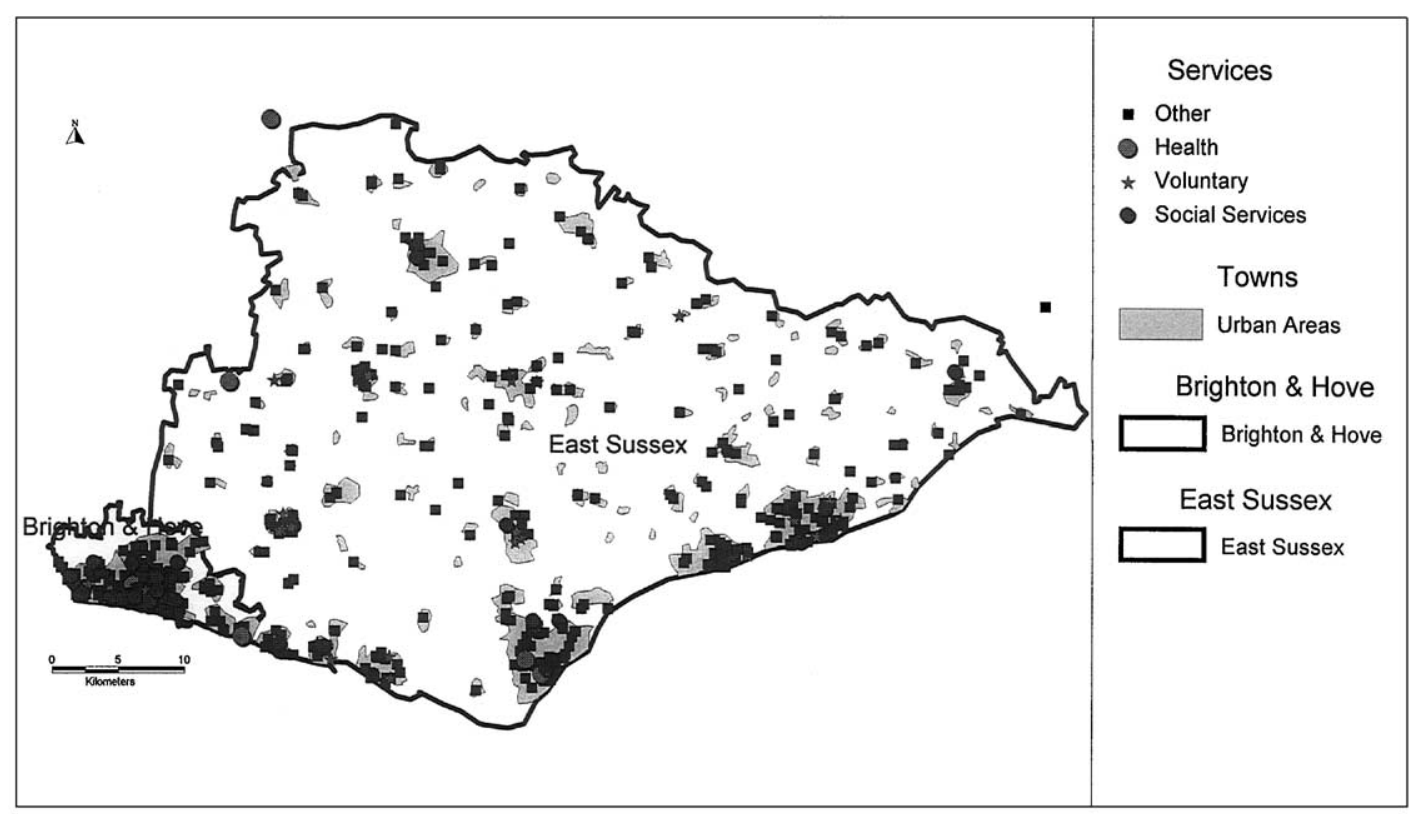

Fig. 2. Short-term care services in East Sussex 1995/6.

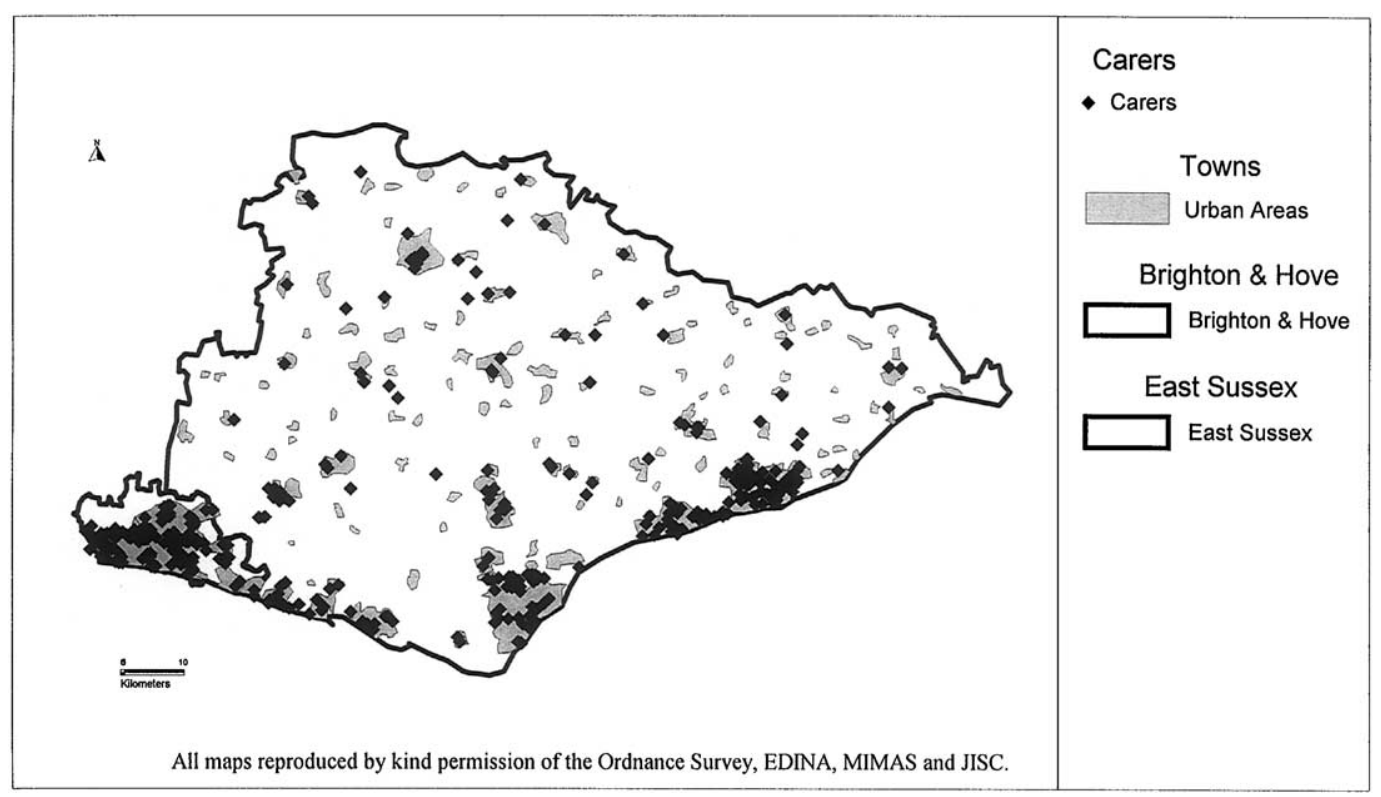

Fig. 3. Informal carer families, East Sussex 1995/6.

There were approximately 80,000 carers in East Sussex as a whole at the last count in 1995 and these carers provided informal care within and outside the home to a wide range of ill and disabled family members and friends (Rowlands, 1998). In the late 1980s and 1990s, Britain had seen an increasing profile for carers, previously a forgotten group in society responsible for providing the state with an estimated additional $£ 34$ billion worth of free care (Nuttall, 1993). In particular there was an increasing emphasis on carers rights to have a rest from caring and for the state to provide these. These breaks had varyingly been described as short-term breaks, respite or short-term care services. The reasons for choosing short-term care were as follows: (1) it provided the complex form of a realistic health and social care service environment where joint 
working initiatives were present; (2) it cut across a number of service providers, in the statutory, private and voluntary sectors. Multi-agency working in a mixed economy of social care are characteristic of service provision in Britain in the late 1990s.

In general, there are a series of different names for these short-term care services such as sitting services, day care, outreach, or respite. For the purposes of this paper, a wider definition of short-term/respite care will be used. Health and Social Services professionals have generally used the term respite care to describe a break that involves an overnight stay of at least one night. However, a broader definition of this type of care is being increasingly used which emphasises the reception of a break for the carer and/or, the person cared for;

"An arrangement whereby children and adults who are normally dependent on regular carers for at least some aspect of their personal care and support, are provided with a break from their primary carer for a short period. This may include residential, domiciliary and home-supported assistance.. It will not exceed three months for adults and no more than four weeks continuous care for children "(Social Services Inspectorate, 1993, para 2.5)

The mention of domiciliary and home-supported services also draws attention to the wider understanding of short-term care as being additionally inclusive of day care and care in the home.

A number of groups require carers especially certain elderly people but this paper concentrates on those caring for severely disabled young people. A key local strategy document which was significant was a jointly developed strategy on services to children with complex needs put together by a mix of agencies in East Sussex (East Sussex Health Authority, 1995). The definition of children with complex needs was "up to age 19 with a severe physical or neurological disability combined with other special needs, maybe a severe learning disability, special medical need, difficulty in communicating by verbal means" (East Sussex Health Authority, 1995). Although there was a more physical disability element to the definition it broadly corresponded to the more severely disabled children and was important in any consideration of how GIS might be implemented. The details of the policy statements and strategic intentions helped set the agenda for the way in which services were likely to be developed as well as more subtly, identifying priority areas which might affect what was not developed. The other consideration in the development of the policy was the need to include carer/user considerations in the development of the policy. This was achieved through the running of a series of User Workshops in late 1998 and early 1999 that travelled around the county, and talking to carers representatives and individual carers about their needs and requirements (East Sussex County Council, 1999). As would be expected issues of quality, local access, flexibility and cost were high on the carer agenda.

Some of the issues discussed in the literature on GIS and caring have included the potential and limitations of GIS with regard to information access, usage and modelling (Twigg, 1990; Twigg, 1992; Bailey, 1994; Worrall, 1994; Haining, 1998). Due to its ability to manage large volumes of data quickly and to readily produce spatially-oriented output, GIS has been perceived of primarily as a management and planning tool. However, the limitations of such an approach are evident when trying to apply GIS in the context of the complex area of planning short-term care services for carers. Within a social care environment some sort of involvement in user needs is essential. The carers' 'needs' need to be taken into account in the planning of the system so that the use of the technology is 'shared' by purchasers, providers and users/carers (Twigg \& Atkin, 1993; Stalker, 1996). Although such active end-user involvement is not something which planners and providers always encourage, it is becoming increasingly relevant with changes in the organisation of the NHS, social services and local government (Department of Health, 1997; Department of Employment, Trade and the Regions, 1998; Department of Health, 2000).

To more fully realise the aim of considering awareness of GIS in the study area, it is important to directly consider the local service provision issue. An additional aim is to develop case studies out of local policy frameworks. This involves examining a series of spatial issues identified as important in strategy documents (East Sussex Health Authority, 1995; East Sussex County Council, 1999). These issues include location, access, gaps \& omissions, amount and utilisation of services, specialist provision, the spatial distribution of demand and supply and projections of future demand (Joseph \& Phillips, 1984; Gesler, 1986; Hoefer et al., 1994). The quality and cost of services was also a significant factor for both general and more specific spatial aspects of planning (Chisholm, 1995; Foley \& Frost, 1996; Lindsay, 1996; Netten, 1996). This spatial approach to the needs of a short-term care provision also focuses on carer and service provider needs, looks at the relationship to the current service provision, what goals, restraints and other resource implications exist in planning changes to the system and looks at the planning information implications of adopting a spatial/GIS based approach as part of that planning and delivery process. Clearly, it is not possible to analyse all these issues. Instead, the research focused on the issues where relevant data was already available that could be incorporated into a GIS. This allowed the project to produce GIS output which could be used as a tool to test the potential of GIS. 


\section{Method}

A number of methods were used to address the aims of identifying GIS awareness. The first of these was to carry out interviews with key local agencies and service gatekeepers to begin the process of identifying service issues which might be modelled within a GIS. The structuring of the GIS was a second phase and followed traditional GIS data approaches in developing, collection and entering specific qualitative and quantitative data layers (Birkin et al., 1996; Chrisman, 1997; Longley et al., 1999). A final element of the method was to present some of the GIS data outputs to local strategic planners and users to help identify with some illustrative examples those elements of a GIS modelling approach which might be perceived as both positive and problematic.

An important element in structuring the research was to identify through a semi-structured interview the level of GIS awareness and the key geographical issues as understood by managers and planners across the different sectors involved in the provision of short-term care services and to establish the preliminary availability of data resources. The majority of the interviews were carried out in late 1995 and early 1996 and in total 27 individuals were interviewed. The interviewees were identified in part from discussions with the East Sussex Care for the Carers Council and in part through a process of direct contact with the agencies. They were drawn from a number of different sectors including, health (5), social services (9), special education (6), voluntary sector (5), private sector (1) and an external GIS unit (1). ${ }^{1}$ The interviews used a semi-structured technique with a number of key issues for discussion which are listed in Table 2.

The maps were produced using a range of currently available data. The process of data collection, matching and development is described in more detail elsewhere (Foley, 2000). It is not the intent of this paper to go into great depth on the precise technical processes involved though the data collection and the derivation of the datasets is shown in Fig. 4. Much of the raw data was provided with a variety of geographical referencing, ranging from individual unit postcode to broader postcode sector level. Additionally, individual services needed to be referenced by national grid co-ordinate. This process was carried out by using a variety of processes. These included matching unit postcodes

\footnotetext{
${ }^{1}$ The organisations interviewed included East Sussex Health Authority, East Sussex Social Services, East Sussex Special Education Service, Care for the Carers, East Sussex Disability Association, Network of Parents for Children with Disabilities, South Downs NHS Trust, a number of heads of Special Schools and a specialist GIS information unit externally (Hull City Council).
}

Table 2

Semi-structured interview schedule 1995/6

Discussion points

Personal involvement in strategic or other planning areas? Involvement in short-term/respite care services?

Current key policy and planning issues currently involved with? Knowledge and use of GIS ?

Awareness of value of using GIS and/or spatial information for planning and decision making purposes?

Other issues relevant to GIS use?

Data availability and problems?

against enumeration district (ED) centroids. This latter approach was also useful in providing a natural masking process which helped anonymise the individual level data. Other data was aggregated up to ward and postcode sector level. All of the information was stored as thirty four separate layers within the two GIS, MapInfo v5.0 and ArcView v3.2. These programs were chosen as they were partially used in the appropriate agencies and were also more widely used in the statutory sector. A choice was also made to develop the databases in parallel to show the relative ease of transferability between the different GIS.

In developing a GIS to aid the health and social care planning associated with short-term care, there were a number of layers of information to be entered. Key data layers were created within a number of broad areas. These included topographic, geo-demographic, service and user location layers. Data on the location, size and accessibility of service centres and providers was created for different sectors, statutory, voluntary and private. Alongside this information on services, a series of layers were entered containing information on the carers with information on disabilities, services used, age, gender and other variables. This data was collected through a number of different approaches including direct interviews with data providers and by collecting anonymised lists of children with disabilities from statutory organisations. The principal GIS layers are listed in Table 3.

By amalgamating the data in this way it is possible to look at the distribution of different aspects of service provision, demand, accessibility and utilisation. One common approach in using GIS in modelling service provision is the simple but valuable graphical presentation of information. Examples showed the distribution of the amount of care received by users. This was gathered from data held by the respite care centres within the study areas and initially identified at point level the different amounts of care individual children received. A second and linked element is the ability of a GIS to map this service provision at an aggregated geographical level. This is a form widely used for mapping service delivery and has the additional 
Qualitative Data

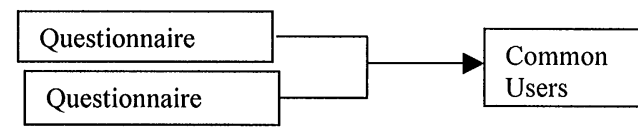

Census Data

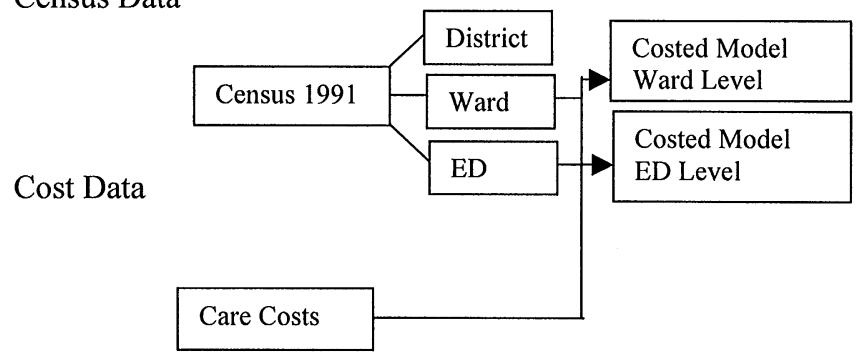

Service Data

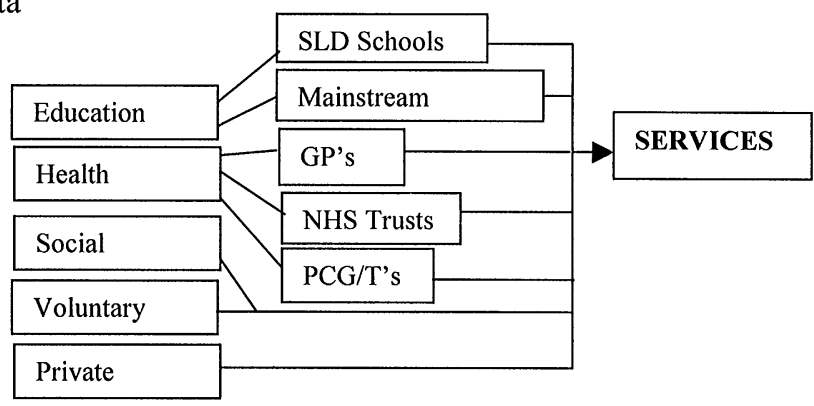

\section{User/Carer Data}

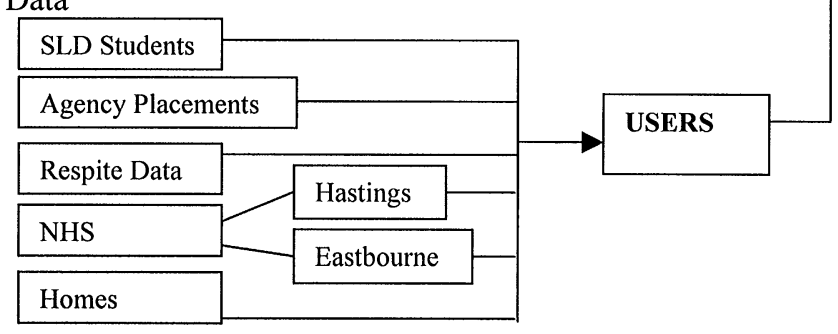

USERS $v 1$ (Real)

USERS v2

(Real/Proxy

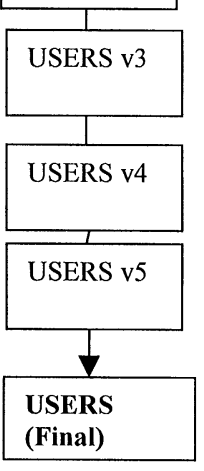

Fig. 4. Derivation of data sets.

advantage of aggregating point data into areas, thereby preserving confidentiality. Fig. 5 identifies the provision of care at two different areal levels, Postcode Area and Ward. The areal level used in mapping could also be modified according to the reporting and planning requirements of the agencies.

As GIS are, at their simplest, databases linked to digital maps, it is equally possible to derive basic statistical and quantitative information which helped to identify service need. One way in which modelling was developed was by looking at the specifics of 'estimated' versus 'met' need in more detail. This was modelled by identifying from service provision and cost data, a theoretical amount which was spent on the services (£486,365) and compared this to a theoretical amount expressed as providing an optimum service to carers $(£ 2,023,895)$. In each case, the amount was the sum for each individual carer family and was based on identified optimum service provision from a carer perspective (Foley \& Frost, 1996). This could also be mapped at different spatial levels to more accurately identify within the local area as to where this shortfall was most intense and to model where equity of service delivery was lacking. From a user perspective this may be a double-edged sword in that it helps to identify those carers who are 'over' as well as 'under-supplied' (Foley, 2000). 
Table 3

Key GIS layers

\begin{tabular}{|c|c|c|c|c|}
\hline Layer description & Layer name & No. of records & Source agency & Description \\
\hline Enumeration districts & Edlist & 1620 & $\begin{array}{l}\text { MIMAS-University of } \\
\text { Manchester }\end{array}$ & $\begin{array}{l}\text { Census data at ED level—both } \\
\text { authorities }\end{array}$ \\
\hline Local authority Districts & Esussdis & 7 & $\begin{array}{l}\text { EDINA-University of } \\
\text { Edinburgh }\end{array}$ & District boundaries \\
\hline Respite care centres for children & Kidresp & 3 & Digitised on-sceen & Resource centres for children \\
\hline Services outside East Sussex & $\mathrm{OOC}$ & 26 & Digitised on-sceen & $\begin{array}{l}\text { Short-term care services outside } \\
\text { of study area }\end{array}$ \\
\hline Primary care groups & PCGs & 6 & $\begin{array}{l}\text { East Sussex Brighton \& } \\
\text { Hove health authority }\end{array}$ & Primary care groups \\
\hline Postcode district & Postcode & 41 & Digitised on-sceen & Postcode district boundaries \\
\hline Railway line & Railway & 10 & EDINA & Railway lines \\
\hline Service users & Realist 15 & 409 & Digitised on-sceen & $\begin{array}{l}\text { All carer families in both } \\
\text { authorities }\end{array}$ \\
\hline Road network & Roadsuss & 11833 & EDINA & All roads at $1: 250,000$ scale \\
\hline Services for short-term care & Services & 674 & Digitised on-sceen & All short-term care services. \\
\hline $\begin{array}{l}\text { Special schools for severely } \\
\text { disabled }\end{array}$ & SLD & 5 & Digitised on-sceen & $\begin{array}{l}\text { Severe learning disability } \\
\text { schools }\end{array}$ \\
\hline Qualitative carer survey & Sldcarer & 123 & Local survey data & User survey 1991 data \\
\hline Railway stations & Station & 42 & Digitised on-sceen & Railway stations \\
\hline Urban areas & Towns & 124 & Digitised on-sceen & Urban areas at $1: 250,000$ scale \\
\hline Electoral wards & Ward & 140 & MIMAS & $\begin{array}{l}\text { Census data at ward data- } \\
\text { both authorities }\end{array}$ \\
\hline
\end{tabular}

A final method for calculating the relationship between demand and 'met' need is to use the GIS to map carers receipt of care against their perceived need for care. This begins to identify some interesting spatial results when need (as expressed by average disability score) is compared to provision. By looking at the distribution of the levels of need as expressed by levels of disability (available as an individual score within NHS Trust data) and mapping this against levels of provision it became possible to further identify lack of equity across the county, particularly in rural areas (Fig. 6). Fig. 6 even seemed to indicate that proximity to service location had a greater impact than specific disability levels though the absence of a full data set of receipt of care meant that such results needed to be treated with extreme caution. Additionally, the pattern was not consistent throughout the county. Although an initial hypothesis suggested that rural areas were less well served in terms of demand and 'met' need, Fig. 6 suggested that this was not the case in all urban areas, especially Eastbourne.

From a qualitative point of view, one of the data sources used to match users across data-sets was a survey of 170 children with disabilities carried out at the University of Brighton in 1991 to look at those children's use of holiday respite within the study area. Although the data did not match the main user layer in date terms, relating instead to service use from 4 years previously, it was still possible, using locational and age date to match 46 of these users to the wider data set.
This information was used in part to help develop proxy measures of day and home care use, and the difference in date helped mask the data for confidentiality purposes. The data gathered from this survey contained a mix of coded and non-coded responses about the utilisation of and satisfaction with, services. This data was linked to the layer relating to users and it was then possible to start to look at ways of mapping free text responses. Since GIS data querying also dealt with text answers it was possible to produce maps related to the question on need and satisfaction with service provision. This qualitative response map (Fig. 7) provided an interesting perspective on service use and even more interestingly, helped to 'spatialise' carer's perspectives on the quality of service provision. This meant that in the same way as proximity mapping helped to identify anomalous individuals, a clustering of unsatisfactory responses would help identify potential problems with the quality of service provided, an issue very close to carers' hearts. The approach was to do free text spatial queries that focused on negative responses that were broadly characterised as "not enough", "need" and "more" ! In the case of Fig. 7, there was a small clustering of "not enough" responses that might prove as an interesting link for planners to develop with carers. The use of such approaches was not unproblematic, not least because of the small sample size. However, the ability, through the use of spatial identifiers, to geo-reference qualitative questionnaire responses to quantitatively collected data provides an important methodological link between the 


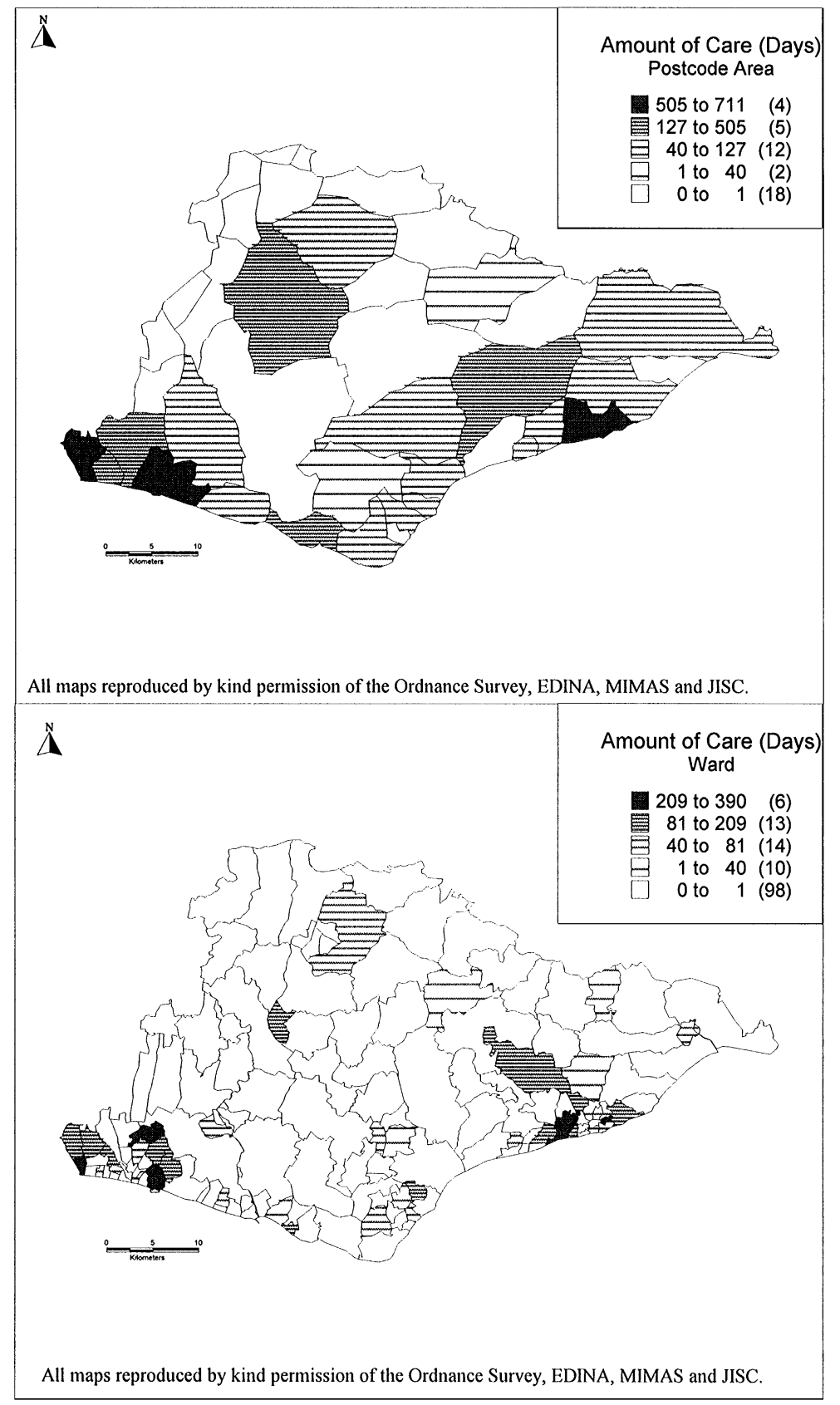

Fig. 5. Areal maps of amounts of care: East Sussex 1995/6.

system and the human, the objective and the subjective and helps to personalise the data. This link with wider cultural geography's ethnographic methodologies emphasised the personal, health behavioural elements and the subjective as valid voices within a planning process and represents at least a starting point to fully represent all perspectives within an integrated GIS system (Couclelis, 1997; Kearns \& Gesler, 1996).
A final set of tabular spatial results were also derived spatially from the GIS and showed the value of a GIS for simple statistical data presentation. The principal statistical summaries which planners would be interested in at broad geographical levels were presented in Table 4. The table showed summary statistics for districts and primary care groups (PCG) but could be expanded to produce ward and even ED level summaries 


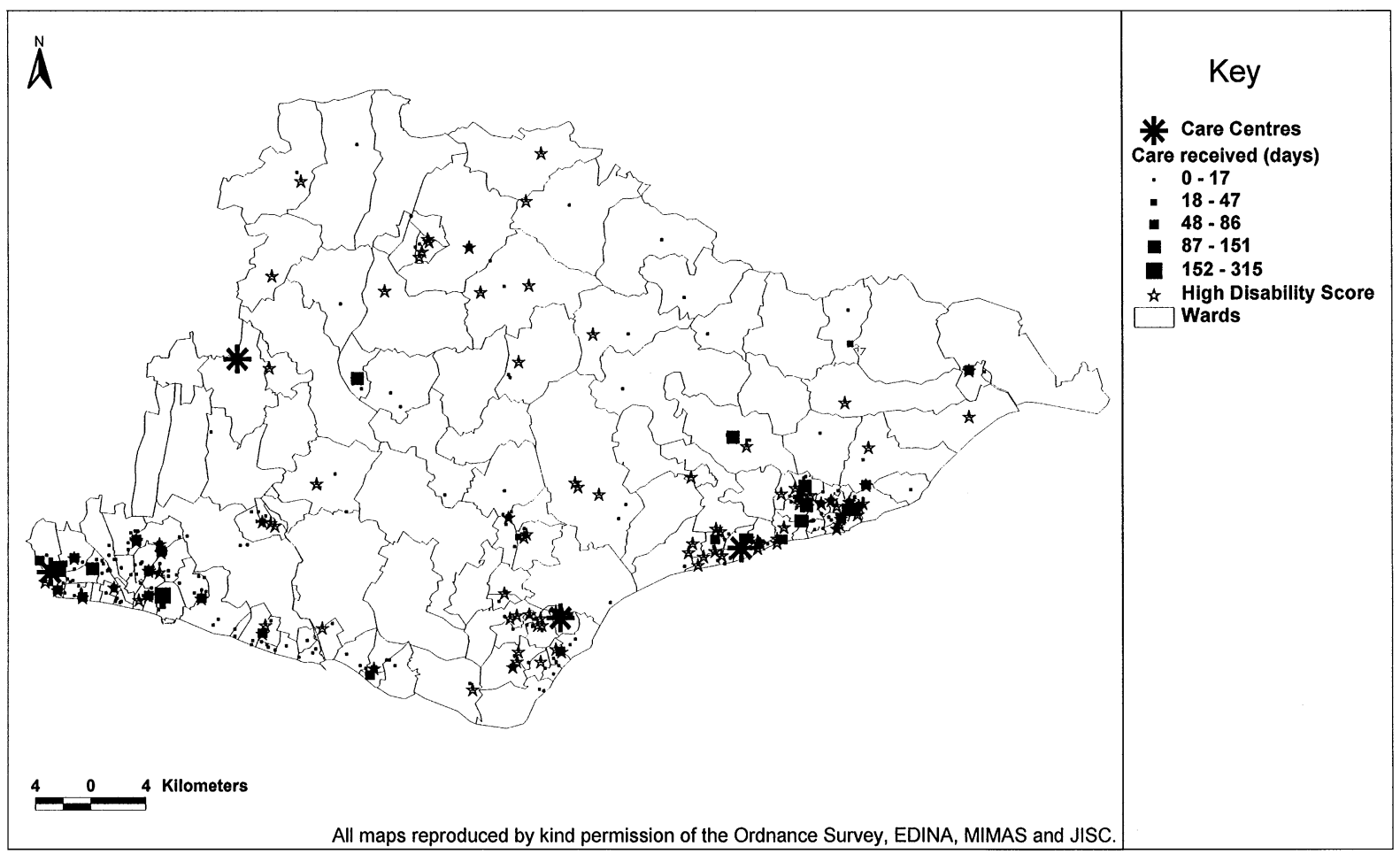

Fig. 6. Service provision and need: East Sussex 1995/6.

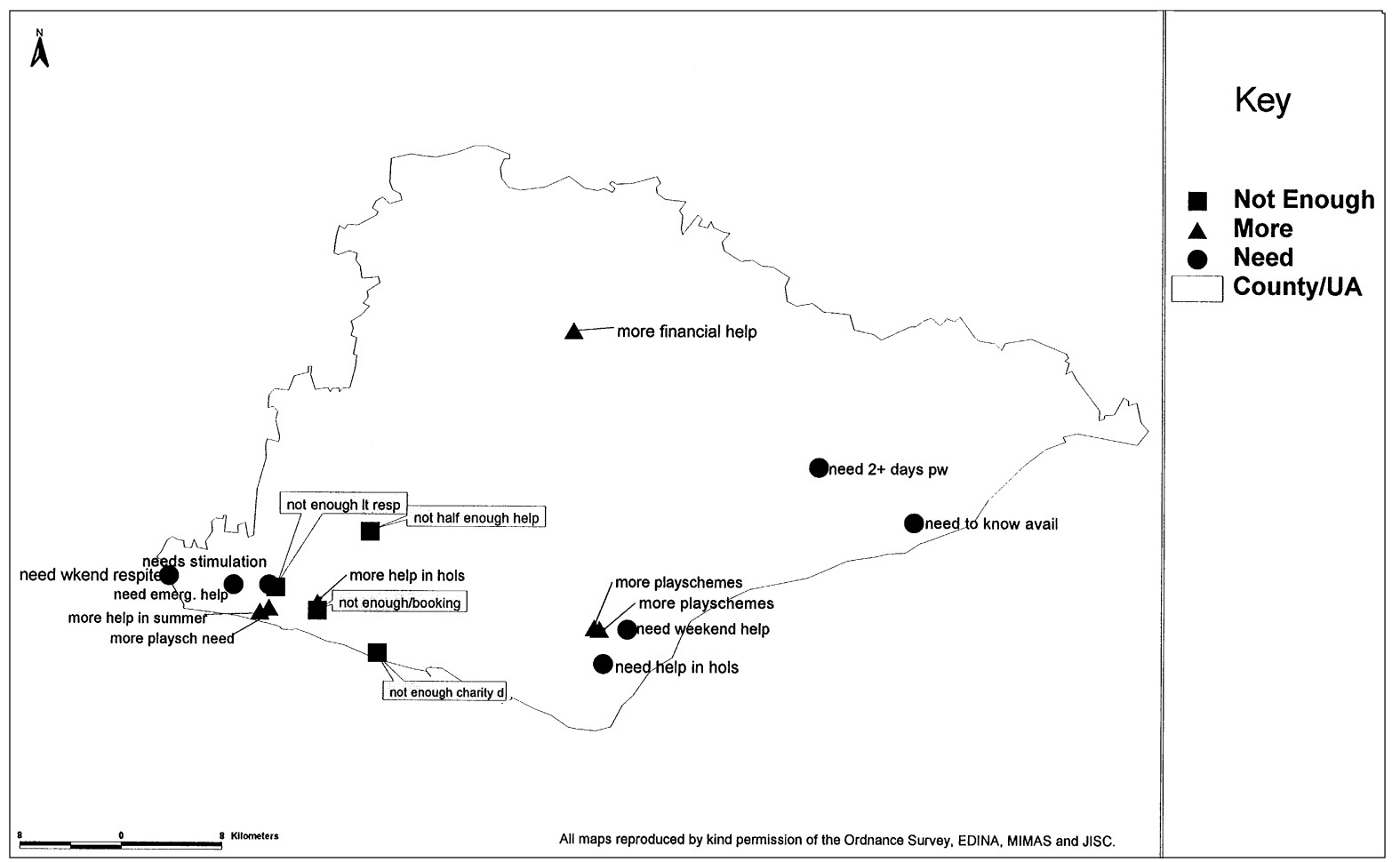

Fig. 7. Sample map of qualitative responses. 
GIS-derived ouptut for short-term care in East Sussex ${ }^{\mathrm{a}}$

Total no. of users Respite care (h) Mean RC (h) Day care (h) Mean DC (h) Home care (h) Mean HC (h) Tcost Optcost Variance Mean distresp Mean distsch

\begin{tabular}{|c|c|c|c|c|c|c|c|c|c|c|c|}
\hline \multicolumn{12}{|l|}{ District } \\
\hline Brighton & 74 & 874 & 11.81 & 133 & 1.80 & 0 & 0.00 & 90227 & 191190 & $-100963 \quad 5.1$ & 3.7 \\
\hline Hove & 54 & 809 & 14.98 & 33 & 0.61 & 0 & 0.00 & 71227 & 143426 & $-72199 \quad 1.6$ & 3.6 \\
\hline Eastbourne & 41 & 241 & 5.88 & 8 & 0.20 & 13 & 0.32 & 43816 & 264868 & $-221052 \quad 3.4$ & 3.4 \\
\hline Hastings & 72 & 1278 & 17.75 & 30 & 0.42 & 0 & 0.00 & 115871 & 461516 & $-345645 \quad 6.3$ & 5.2 \\
\hline Lewes & 49 & 223 & 4.55 & 49 & 1.00 & 8 & 0.16 & 51843 & 197165 & $-145322 \quad 8.7$ & 11.8 \\
\hline Rother & 58 & 404 & 6.97 & 0 & 0.00 & 5 & 0.09 & 65470 & 384669 & -3191996 & 5.7 \\
\hline Wealden & 59 & 237 & 4.02 & 0 & 0.00 & 69 & 1.17 & 65849 & 386991 & -3211429.2 & 6.5 \\
\hline $\mathrm{B} \& \mathrm{H}$ mean & & & 13.14 & & 1.3 & & $\mathbf{0}$ & 80727 & 167308 & -865813.35 & 3.65 \\
\hline B\&H total & 128 & 1683 & & 166 & & 0 & & 161454 & 334616 & $-173162 \quad 6.7$ & 7.3 \\
\hline ES mean & & & 8.54 & & 0.31 & & 0.34 & 68570 & 339042 & $-\mathbf{2 7 0 4 7 2} 6.72$ & 6.52 \\
\hline ES total & 279 & 2383 & & 87 & & 95 & & 342849 & 1695209 & -135236033.6 & 32.6 \\
\hline Average & 58 & & 9.99 & & 0.62 & & 0.23 & 72043 & 289975 & $-217932 \quad 5.76$ & 5.70 \\
\hline Total & 407 & 4066 & & 253 & & 95 & & 504303 & 2029825 & -1525522 & \\
\hline \multicolumn{12}{|l|}{$P C G$} \\
\hline Bexhill \& Rother & 55 & 404 & 7.35 & 0 & 0.00 & 5 & 0.09 & 63213 & 365370 & $-302157 \quad 5.7$ & 6.2 \\
\hline Brighton \& Hove & 128 & 1683 & 13.15 & 166 & 1.30 & 0 & 0.00 & 161454 & 334616 & $-173162 \quad 3.4$ & 3.7 \\
\hline Eastbourne Downs & 76 & 437 & 5.75 & 8 & 0.11 & 15 & 0.20 & 81795 & 461402 & $-379607 \quad 4.6$ & 5.7 \\
\hline Hastings & 75 & 1278 & 17.04 & 30 & 0.40 & 0 & 0.00 & 118128 & 480815 & $-362687 \quad 6.3$ & 5.1 \\
\hline High weald & 34 & 168 & 4.94 & 0 & 0.00 & 67 & 1.97 & 41582 & 221102 & -17952018.1 & 6.3 \\
\hline Ouse valley & 39 & 96 & 2.46 & 49 & 1.26 & 8 & 0.21 & 38131 & 166520 & -1283895.6 & 11.7 \\
\hline Average & 68 & 678 & 8.45 & 42 & 0.51 & 16 & 0.41 & 84051 & 338304 & $-254254 \quad 7.28$ & 6.45 \\
\hline Total & 407 & 4066 & & 253 & & 95 & & 504303 & 2029825 & -1525522 & \\
\hline
\end{tabular}

${ }^{\mathrm{a}}$ Notes:

Tcost is a variable measured the total cost of care provided to carers in each area

Optcost is a derived variable identifying the cost of 'optimal' service provision in each area.

Variance is the difference between Tcost and Optcost

Meandistresp is the average distance to the nearest respite care centre for carers in each area.

Meandistsch is the average distance to the nearest SLD school for carers in each area. 
where more detailed local areal comparisons needed to be carried out. The value of using the broad level approach in Table 4 was shown by the way in which variability between Brighton \& Hove and the remaining East Sussex was clarified. For example, the average variance score between service need and provision for Brighton \& Hove at $-86,581$ was over three times smaller than the score, $-270,472$, for East Sussex indicating that carers in the latter authority were generally better served against need. At another level, those districts and PCGs within the study area that are better served for respite care provision can be clearly identified in Table 4. Again, the average amount of respite received per carer was considerably higher in Brighton \& Hove (13.14) than for East Sussex (8.54). The data for day and home care was much less reliable however, due to the limited amount available. These statistical results were derived on spatial procedures from within the GIS and provided valuable spatial summaries matched to the broad themes, service provision, need, demand, distance and accessibility. This tabular frame could also be revised as new information was gathered, new services opened or existing services closed.

Two workshops were held which were intended to follow up the initial semi-structured interviews. The aim of these sessions was to present some of the case study outcomes to a knowledgeable audience to identify the specific areas of most interest in an applied setting and to receive an informed and critical perspective on the modelling which had already been carried out. The first workshop was held with a group of senior health authority, social services and primary care group management staff as well as user representatives from a carers lobby group (15 in total), while the second workshop addressed a group of user representatives of Sussex PCGs (10 in total). The structure of both workshops were a short presentation on GIS, some examples from work locally and then a wider session talking about responses, criticisms and wider policy discussion about any potential GIS might have. The latter workshop also worked through a SWOT analysis of GIS potential in health and social care planning.

\section{Findings}

The semi-structured interviews were also designed to produce some basic quantitative findings out of the discussion points. $48 \%$ (13) of the respondents had heard of GIS (principally at Local Authority level) and $52 \%$ (14) had not. This illustrates the difficulty of doing a functional needs assessment in an environment where knowledge is limited. About 22\% (6) of the respondents had also used a GIS in some form. Once made aware of the nature of GIS, $74 \%$ (20) saw a potential value for
GIS in their area, while 4\% (1) said that they saw little or no value and $22 \%$ (6) saw a possible/limited value though they felt that this was compromised from the start by the complexity of the field. It should be pointed out for comparative purposes that no attempt was made to make a distinction between GIS and computerised cartography as was the case in the surveys carried out by Gould (1992) and Smith \& Jarvis (1998). Additionally, many of the respondents who had heard of GIS had heard of it from other sections of their organisations and thought of it in relation to other wider applications such as highways planning and land-use planning. Perhaps of more value than the summary quantitative data from the questionnaire were the wider discussions about key policy and planning issues and the potential value which the service managers, planners and providers saw for GIS within these areas.

From the summarised responses in the interviews, there were a number of clearly identifiable lines of development for GIS. In terms of a question on current policy and planning issues (Table 2), the mapping of needs $(19 \%)$, mapping to aid the planning of services $(26 \%)$ and the effect of boundary change (37\%) were identified within this wider policy framework. There were a number of detailed responses to how GIS might have potential including, visualisation and spatial display value $(19 \%)$, service location planning $(22 \%)$ and the mapping of health need $(11 \%)$. When grouped into broader categories, it could be seen that a large number of respondents saw at least some value for GIS in the areas of service planning $(48 \%)$, planning for users $(26 \%)$ and the spatial modelling of service delivery $(48 \%)$. These were valuable findings in that they did in part set the agenda for much of the subsequent thinking about which spatial elements to focus on and even which case study areas to develop. More detailed quotes from the interviews give a flavour of these issues and it is particularly interesting to note the potential effect which a lack of awareness among senior managers might have. Quotes on data confidentiality and how GIS was currently used were also valuable.

'.. I'm obviously interested in GIS elements but there isn't the will or the knowledge among senior staff to develop it further..' (Manager, Social Services Information Unit)

'..very concerned about issues of confidentiality. They (Social Services) have a legal agreement with NHS Trusts which is covered by the Data Protection Act. If the data was used externally it would have to be anonymous and also at a level which would not cause concern. Currently investigating strategies and ways around this. Was also concerned about links user groups. Could anonymise, falsify and omit in any public domain productions or agree to work at a 
detailed level on their end but make it broader for publication..' (Senior Manager, Social Services Children \& Families Division)

'..From a health care planning point of view, the main questions we are involved in are the provision of an equitable service, information on how much disease there is in the county and where it is located and what services are needed to cope and how big those services need to be. We mostly use Oracle databases at ward level and apply answers/informational outputs direct from the tables... We generally use GIS as ad-hoc 'supporting information' for staff who make decisions on the provision of services within local areas..' (Senior Manager, Health Authority Information Unit)

From both the literature review and the questionnaire interviews, a number of outcomes were identified in terms of existing knowledge, key issues and concepts. As identified in the literature review, there had been limited work in the specific area of GIS and health and social care planning. A number of reasons had been put forward for this including;

- a lack of IT expertise amongst staff,

- a limited appreciation of spatial aspects of planning,

- limited resourcing and

- the complexity of the planning process (Gould, 19921; Campbell \& Masser, 1992).

Yet, the literature confidently asserted the value of GIS for health care planning within research and practical applications (Barnes \& Peck, 1994; Bertrand \& Mock, 1995) and this needed to be tested more thoroughly to determine the level at which GIS could be applied and to demonstrate the potential value of GIS to practitioners and planners in the field and more widely to carers and the persons they cared for. The interviews suggested that we should have less confidence in the potential of GIS since there were problems in terms of knowledge, verifiable value and a lack of use in strategic planning even by those who were already using GIS within their job.

To test further views on the role of GIS, the especially prepared maps were presented at feedback sessions. The first session with senior health and social care managers raised a number of issues and provided invaluable feedback. During the open session following a demonstration of GIS capabilities, there were a number of questions and comments. The first related to the ease of access to statistical evaluation and the ease with which GIS could carry this out. This is partly identified as one established weakness of GIS in that much of this type of analysis is exported out of GIS into statistical packages (Haining, 1998; Kulldorff, 1999). A second query related to the ability to say plot census date on specific carer sub-groups, specifically lone parents. This was not possible due to lack of data at this level and flagged up the importance of access to the correct data in designing and this engender considerable interest and was seen by the respondents as a good example of where GIS could feed a new perspective into the planning system as well as showed up issues of inequity from a user perspective.

Spatial approaches and ease of access to a GIS-style interface was also discussed though one Health Authority manager raised a query as to how the end user related to different forms of access and questioned whether a spatial rather than text-based approach to service information was really important though there was some disagreement on this point as several of the managers liked the (carto)graphical interface. A significant discussion also took place about data management, data collection and confidentiality with some conflicting views and a general feeling that the geographical levels worked at and presented at would dictate the amount/form of data used and published. This would range from a fairly confidential broad/public interface to a more individual/detailed developer/planner end. Again, the need for this detailed level data was queried and a PCG user representative also gave an example from his working area of using Health Visitor Caseloads as a means of data collecting to be fed back into planning and management within a Trust/PCG environment. In general, there was some good critical feedback about spatial approaches and the most interesting response seemed to be positive:

'..I can see GIS as being complementary rather than alternative approach to data management but without much added effort' (Commissioning Manager, Health Authority).

The second workshop gave some interesting feedback and the use of a SWOT analysis gave the results illustrated in Table 5. One or two respondents felt that the spatial perspective, while useful, would be difficult to sustain without consideration of all the complex aspatial elements as well. Others were more enthusiastic and felt that it would be useful for a number of reasons. The SWOT analysis generally and correctly identified data as a key issue both for positive and negative reasons. It was a key to the comparability and sharing of information but could be abused. There were also concerns about data quality and access. All attendees felt that the "new perspective' produced by a spatial approach would be very helpful to planners and managers and were also interested in the integrated data aspect of a GIS.

Many of the respondents at the workshops were generally positive about the potential of GIS as a complementary planning tool and could see its enhanced value when set against legislative and policy demands on 
Table 5

SWOT analysis of GIS by local PCG representatives

\begin{tabular}{llll}
\hline Strengths & Weaknesses & Opportunities & Threats \\
\hline $\begin{array}{l}\text { Focus of planning on the } \\
\text { local(ity) population }\end{array}$ & $\begin{array}{l}\text { Non-matching information layers } \\
\text { make data integration difficult }\end{array}$ & $\begin{array}{l}\text { New point of view or aspect } \\
\text { on issues }\end{array}$ & Use of the data \\
$\begin{array}{l}\text { Use of travel time rather than } \\
\text { distance for accessibility }\end{array}$ & $\begin{array}{l}\text { Level of application - affected by } \\
\text { boundaries and wider imperatives } \\
\text { Innovative spatial perspective } \\
\text { Could be used in isolation- }\end{array}$ & $\begin{array}{l}\text { Who is in charge and } \\
\text { needs to understand wider context }\end{array}$ & producing output \\
Multi-faceted approach to issues & & & \\
$\begin{array}{l}\text { User-friendly to the non-specialist } \\
\text { (use of maps) }\end{array}$ & & \\
\hline
\end{tabular}

them as purchasers and providers. They were particularly interested in the ability to present data at a number of aggregated levels simultaneously and the capability of querying the GIS to aid the planning of service provision by different age groups. They also identified a number of potential problems which related in part to practical concerns about data issues of confidentiality, availability, IT management and standardisation when applying the GIS across a number of agencies. A second and perhaps more lingering issue related to a questioning of the value of 'spatiality' and a spatial approach and was an issue which had always been more difficult to clarify (Jacquez, 1998; Richards, Croner, Rushton, Brown, \& Fowler, 1999b).

\section{Conclusions}

Planning within health and social care is becoming a key issue again leading into the new century due to fundamental changes in the way in which care is provided and the associated problems of limited resources and changing demands. This applies particularly to carers (Department of Health, 1999). The use of GIS as a methodology to address these problems is likely to become increasingly significant. The relevance of data value, integrity and applicability is however paramount. Moon (1995), speaking about the broader context of the geography of health, points out that;

'Health and health care research has been equally conservative and uncritical in terms of the methods that it has used. These have tended to the quantitative and have frequently lacked design sophistication. Qualitative method offers considerable scope for innovation in place-related health and health care research (Moon, 1995)'

The issue still remains as to whether a GIS can actually deliver and successfully incorporate qualitative data into a fundamentally quantitative structure. This is a debate which needs to be re-examined in the light of the development of GIS systems and also in the light of the changing demands of health care planning. Although the value of technology and systems such as GIS is obvious, the implementation remains one which still needs a considerable amount of thought and development.

While the maps (Figs. 5-7) gave a flavour of the way in which data could be analysed and used from a management and planning perspective, there was little indication that they really took into account particular carer needs issues. These issues were reflected in a number of ways. Firstly, access to data on services was confusing and sometimes difficult for carers and investigation is ongoing to look at ways of improving information access. This information element of a GIS could be improved by output being made available through more accessible forms such as image maps on local community information systems and through the Internet. At another level, data issues such as access, confidentiality and ethics made access to more detailed information a difficult proposition (O'Dwyer \& Burton, 1998). Questions of control of data also needed to be taken into account when designing any system which might aim to satisfy demand across a number of sectors and the whole question of joint working was fraught with difficulty. This also led to difficulties relating to the forms in which data was stored, as GIS store data in a relatively rigid form while attaching qualitative data on needs, individual cases and circumstances were by definition more complex and difficult to clarify in a system environment

The aims of the research were to examine the awareness and applicability of GIS to short-term care planning in East Sussex and to create via the case studies a template for a GIS to carry this out. Feedback from the different methods used in the study suggested a number of positive and negative outcomes which need to be considered if implementation of GIS is to develop in the health and social care environment. It was also not suggested that the GIS would in any way replaced 
existing information management approaches, rather it was presented in context as a technological yet realistic modelling tool to augment the planning process from the perspective of all agents involved. It would subsequently be placed in the hands of planners, purchasers, and users to look at any potential modelled real-life outcomes and real life data to further the decisionmaking process.

In the study undertaken, data on the specific types and levels of disabilities associated with each individual child was partially available via the NHS Trust Registers. This kind of information will be essential in any meaningful modelling of need and demand. Such direct information may remain problematic as ethical issues associated with the use of individual and confidential data remain a major stumbling block in the development of the use of GIS in this area. More widely, the sharing of data within the sort of joint working frameworks, such as joint investment plans (JIP) and health improvement plans (HIMP), which are likely to set agendas for short-term care planning in the near future, will also need to address these issues more closely. This is especially true in the light of recent moves within primary care generally to clarify the position on the use of individual level data in health, especially in relation to 'informed consent'. An example based on the case of $R v$ Department of Health ex parte Source Informatics Ltd identifies a problem with the use of data within a clear framework of 'informed consent' (ACHCEW Press Release, November 1999). The full implications of these discussions are being considered only now and may seriously hamper GIS work in future. In an environment where GIS makes data matching more feasible, this is likely to be a contentious area within wider data sharing settings and has the possibility of slowing the process down when, perversely, one of the advantages of GIS is speedy data collation. It also represents an area, however, where, if correct procedures were to be followed, the validity and utility of data used within a GIS could be made beyond ethical reproach.

A number of key references which informed the research referred to the need to add real human data and match the spatial with the aspatial to make GIS truly valuable in this type of social care setting (Khan \& Bhardwaj, 1994; Wright \& Kerslake, 1995; Couclelis, 1997). Dueto the complex ways in which users use services and make choices, it would be extremely difficult for any automated information system, including a GIS, to model these personal elements in a meaningful way. These issues were reflected in comments in both the semi-structured interviews and feedback session with health professionals and carers, which questioned the real value of GIS until such data could be successfully identified and used within the constraints of data ownership and confidentiality. This will always be problematic for any work in this area. Such a criticism may also be applied to this research where, in the absence of detailed individual information, gaps in such aspatial information were filled by proxy areal data and survey estimates. This challenge is one which this research met in part but there is significant work to do in clearly identifying from the start what the specific ideal, available and usable data sets were. For example, what quantitative data was available, what was missing and what relevant qualitative data could be collected which would help the value of GIS in this area. Additionally, the need for more research in this area which could expressly quantify the value of GIS and geography in an outcome sense was one which health and social care professionals felt would greatly enhance the appeal of GIS to their respective working environments.

\section{References}

Association of Community Health Councils of England and Wales. (1999). Patients' views won't be heard in confidentiality case. London: ACHCEW.

Bailey, T. C. (1994). A review of statistical spatial analysis in geographical information systems. In S. Fotheringham, \& P. Rogerson (Eds.), Spatial Analysis and GIS (pp. 13-44). London: Taylor \& Francis.

Barnes, S., \& Peck, A. (1994). Mapping the future of health care: GIS applications in health care analysis. Geo Information Systems, 4(4), 30.

Berry, D., \& Jarrell, T. W. (1999). Ranking priorities for a state family service integration initiative by census tract in Northern New Castle county, Delaware, 1997. Journal of Public Health Management Practice, 5(2), 57-59.

Bertrand, W. E., \& Mock, N. B. (1995). Spatial Information to make a difference: Value added decision-making in the health sector with geographical information systems. In M. de Lepper (Ed.), The added value of geographical information systems in public and environmental health (pp. 265-276). Den Haag: Kluwer.

Birkin, M., Clarke, G., Clarke, M., \& Wilson, A. (1996). Intelligent GIS. Location decisions and strategic planning. Cambridge: GeoInformation.

Bullen, N., Moon, G., \& Jones, K. (1996). Defining localities for health planning-A GIS approach. Social Science \& Medicine, 42(6), 801-816.

Burns, S. (1995). Health practices - a desktop map project thrives at Avon health. Mapping Awareness, 9(5), 34-37.

Campbell, H., \& Masser, I. (1992). The impact of GIS on local government in Great Britain. In T. W. Rideout (Ed.), Geographic information systems in urban \& rural planning (pp. 14-25). Edinburgh: Institute of British Geographers (PESG).

Carers National Association. (1994). A stronger voice: The achievements of the carers' movement 1963-1993. London: Carers National Association.

Chisholm, M. (1995). Geographic information systems: A tool for human service professionals. New Technology in the Human Services, 8(3), 18-22. 
Chrisman, N. (1997). Exploring geographic information systems. New York: Wiley.

Clarke, M., Chesworth, J., Harmer, J., McDonald, A., Sui, Y. L., \& Wilson, A. (1993). Intelligent, interactive and analysisbased GIS: Principles and applications. In P. M. Mather (Ed.), Geographical information handling-research and applications (pp. 325-337). London: Wiley.

Cooper, D. (1999). Looking below the surface. Mapping Awareness, 13(7), 22-25.

Couclelis, H. (1997). GIS without computers: Building geographic information from the ground up. In Z. Kemp (Ed.), Innovations in GIS 4 (pp. 219-226). London: Taylor \& Francis.

Curtis, S., \& Jones, I. (1998). Is there a place for geography in the analysis of health inequality? Sociology of Health \& Illness, 20(5), 645-672.

Curtis, S., \& Taket, A. (1996). Health and societies: Changing perspectives.. London: Edward Arnold.

DeMers, M. N. (1997). Fundamentals of geographic information systems. New York: John Wiley.

Department of Environment, Trade and the Regions. (1998). Modern local government: in touch with people (CM4014). London: Stationary Office.

Department of Health. (1995). The carers (recognition \& services) act. London: HMSO.

Department of Health. (1997). The new NHS: Modern, dependable (CM3807). London: Stationery Office.

Department of Health. (1998). Modernising social services (CM4169). London: Stationary Office.

Department of Health. (1999). Caring for carers. A national strategy. London: Stationary Office.

Department of Health. (2000). The NHS plan. A plan for investment. A plan for reform (CM4818-I). London: Stationary Office.

Dowie, P., Koval, S., Burnhill, P., \& Healy, R. (1991). GIS and community health care: A case study of geriatric service provision. Proceedings of the European Conference on GIS, EGIS '91 (pp. 267-276). Utrecht: Kluwer.

East Sussex County Council. (1999). Respite care strategy. Lewes: East Sussex County Council.

East Sussex Health Authority. (1995). Draft east Sussex strategy for services for children with complex needs. Eastbourne: East Sussex Health Authority.

Foley, R. (2000). The application of geographical information systems (GIS) to health care planning. Ph.D. thesis. University of Brighton, unpublished.

Foley, R., \& Frost, P. (1996). Who cares for the carers? and how much does it cost? Mapping Awareness, 10(5), 28-31.

Gatrell, A., \& Löytönen, M. (Eds.), (1998a). GIS and health. London: Taylor \& Francis.

Gatrell, A., \& Löytönen, M. (1998b). GIS and Health research: An Introduction. In A. Gatrell, \& M. Löytönen (Eds.), GIS and Health (pp. 3-16). London: Taylor \& Francis.

Gatrell, A., \& Naumann, I. (1992). Hospital location planning: A pilot GIS study. Proceedings of the mapping awareness conference '92 (pp. 257-268). Birmingham: Miles Arnold.

Gatrell, A., \& Senior, M. (1999). Health and health care applications. In P. Longley, D. Maguire, M. Goodchild, \& D. Rhind (Eds.), Geographical information systems: Princi- ples, techniques, applications and management (pp. 925-938). London: Wiley.

Gesler, W. (1986). The uses of spatial analysis in medical geography: A review. Social Science \& Medicine, 23(10), 963-973.

Gould, M. (1992). The use of GIS and CAC by health authorities: Results from a postal questionnaire. Area, 24(4), 391-401.

Haining, R. (1998). Spatial statistics and the analysis of health data. In A. Gatrell, \& M. Löytönen (Eds.), GIS and health (pp. 29-47). London: Taylor \& Francis.

Hirschfield, A., Batey, P., Brown, P., \& Marsden, J. (1990). The spatial epidemiology of food poisoning in Blackpool, Wyre and Fylde: Preliminary results. Working paper 14, Liverpool, URPERRL.

Hoefer, R. A., Hoefer, R. M., \& Tobias, R. A. (1994). Geographic information systems and human services. Journal of Community Practice, 1(3), 113-128.

Huxhold, W. E, \& Levinsohn, A. G. (1995). Managing geographic information systems projects. Oxford: O.U.P.

Jacquez, G. M. (1998). GIS as an enabling technology. In A. Gatrell, \& M. Löytönen (Eds.), GIS and health (pp. 17-28). London: Taylor \& Francis.

Joseph, A. E., \& Phillips, D. R. (1984). Accessibility and utilization: Geographical perspectives on health care delivery. New York: Harper \& Row.

Kearns, R., \& Gesler, W. (Eds.), (1996). Putting health into place. Syracuse: Syracuse University Press.

Khan, A. A., \& Bhardwaj, S. M. (1994). Access to health care-a conceptual framework and its relevance to health care planning. Evaluation and the Health Professions, 17(1), 60-76.

Kulldorff, M. (1999). Geographic information systems (GIS) and community health: Some statistical issues. Journal of Public Health Management and Practice, 5(2), 100-106.

Lindsay, M. (1996). The conundrum of quality. In K. Stalker (Ed.), Developments in short-term care: Breaks and opportunities (pp. 71-82). London: Jessica Kingsley.

Longley, P., Maguire, D., Goodchild, M., \& Rhind, D. (Eds.) (1999). Geographical information systems: Principles, techniques, applications and management. London: Wiley.

Melnick, A. L., \& Fleming, D. W. (1999). Modern geographic information systems: Promise and pitfalls. Journal of Public Health Management and Practice, 5(2), viii-x.

Milligan, C. (2000). 'Breaking out of the asylum': Developments in the geography of mental ill-health - the influence of the informal sector. Health \& Place, 6(3), 189-200.

Moon, G. (1995). (Re)placing research on health and health care. Health \& Place, 1(1), 1-4.

Netten, A. (1996). Costing breaks and opportunities. In K. Stalker (Ed.), Developments in short-term care: Breaks and opportunities (pp. 55-70). London: Jessica Kingsley.

Nuttall, S. R. (1993). Financing long-term care in Great Britain. London: Institute of Actuaries.

O'Dwyer, L., \& Burton, D. (1998). Potential meets reality: GIS and public health research in Australia. Australian and New Zealand Journal of Public Health, 22(7), 819-823.

Phillips, L. J. (1998). Combining quantitative and qualitative approaches to social research in human geography - an impossible mixture? Environment and Planning A, 30, 261276. 
Poulsen, M. F. (1994). Human geography and its relationship to GIS-A perspective from the vantage point of GIS. Australian Geographer, 25(2), 170-177.

Reeves, D., \& Petch, J. (1999). GIS organisations and people: A socio-technical approach. London: Taylor \& Francis.

Richards, T., Croner, C., \& Novick, L. (1999a). Geographic information systems for state and local public health practitioners, Part 2. Journal of Public Health Management and Practice, 5(4), 1-6.

Richards, T. B., Croner, C., Rushton, G., Brown, C. K., \& Fowler, L. (1999b). Geographic information systems and public health: Mapping the future. Public Health Reports, 114, 359-373.

Roper, W. J., \& Mays, G. P. (1999). GIS and public health policy: A new frontier for improving community health. Journal of Public Health Management and Practice, 5(2), vivii.

Rowlands, O. (1998). Informal carer. Results from an independent study carried out on behalf of the Department of Health as part of the 1995 general household survey. London: HMSO.

Rushton, G. (1998). Improving the geographic basis of health surveillance using GIS. In A. Gatrell, \& M. Löytönen (Eds.), GIS and health (pp. 63-79). London: Taylor \& Francis.
Smith, R., \& Jarvis, C. (1998). Just the medicine: GIS uptake in the NHS. Mapping Awareness, 12(7), 30-33.

Social Services Inspectorate. (1993). Guidance on standards for short term breaks. London: HMSO.

Stalker, K. (1996). Developments in short-term care: Breaks and opportunities.. London: Jessica Kingsley.

Twigg, L. (1990). Health based geographical information systems: Their potential examined in the light of existing data sources. Social Science \& Medicine, 30(1), 143-155.

Twigg, J. (1992). Carers in the service system. In J. Twigg (Ed.), Carers. Research and Practice. London: HMSO.

Twigg, J., \& Atkin, K. (1993). Carers perceived: Policy and practice in informal care. Buckingham: OU Press.

Wain, R. (1997). Care in the profiled community. Mapping Awareness, 11(4), 30-32.

Wilkinson, P., Grundy, C., London, M., \& Stevenson, S. (1998). GIS is Public Health. In A. Gatrell, \& M. Löytönen (Eds.), GIS and Health (pp. 179-189). London: Taylor and Francis.

Worrall, L. (1994). Justifying investment in GIS: a local government perspective. International Journal of GIS, 8(6), 545-565.

Wright, J., \& Kerslake, A. (1994). Modelling community care: helping to plan service provision. Community care Management and Planning, 2(1), 5-13. 